\title{
ISG15 Positive
}

National Cancer Institute

\section{Source}

National Cancer Institute. ISG15 Positive. NCI Thesaurus. Code C150648.

An indication that expression of ISG15 has been detected in a sample. 